\title{
Sirolimus is efficacious in treatment for extensive and/or complex slow-flow vascular malformations: a monocentric prospective phase II study
}

Jennifer Hammer, Emmanuel Seront ${ }^{2}$, Steven Duez ${ }^{1}$, Sophie Dupont ${ }^{3}$, An Van Damme ${ }^{4}$, Sandra Schmitz ${ }^{5}$, Claire Hoyoux ${ }^{6}$, Caroline Chopinet ${ }^{7}$, Philippe Clapuyt ${ }^{8}$, Frank Hammer ${ }^{9}$, Miikka Vikkula ${ }^{10}$ and Laurence M. Boon ${ }^{1,10^{*}}$

\begin{abstract}
Background: Extensive and complex vascular malformations often cause chronic pain and severe functional restraint. Conventional treatments, such as surgery and/or sclerotherapy, are rarely curative, underscoring the great need for new therapeutic modalities. Recent preclinical and clinical data demonstrated that sirolimus could offset the progression of vascular malformations and significantly improve quality of life of patients through inhibition of the Phosphatidylinositol3-kinase (PI3K)/AKT/mammalian Target of Rapamycin (mTOR) pathway. The purpose of this prospective study was to assess the efficacy and safety of this treatment in patients with extensive or complex slow-flow vascular malformations.
\end{abstract}

Methods: Sirolimus was administered orally on a continuous dosing schedule with pharmacokinetic-guided target serum concentration level of 10 to $15 \mathrm{ng} / \mathrm{ml}$. Patients were seen every month for the first three months and subsequently every three months. The primary endpoints were safety and efficacy, based on clinical, biological and radiological evaluations, as well as a quality of life questionnaire.

Results: Nineteen patients, from 3 to 64 years old, with lymphatic (LM), venous (VM) or complex slow-flow malformations, refractory to standard care, were enrolled and received sirolimus continuously. After 12 months of follow-up, 16 patients were available for assessment of efficacy and safety: all had a significant and rapid improvement of their symptoms and quality of life. In two patients, sirolimus treatment permitted sclerotherapy and surgery, initially evaluated unfeasible. Sirolimus was well tolerated, with mucositis as the most common (10\% of patients) grade 3 adverse event.

Conclusions: Sirolimus was efficient in extensive LM, VM and/or complex malformations that were refractory to conventional treatments and was well tolerated.

Keywords: Sirolimus, Rapamycin, Venous malformation, Lymphatic malformation, Complex vascular malformation, Slow-flow anomaly, Extensive vascular anomaly

\section{Background}

Vascular malformations are rare structural anomalies of blood and lymphatic vessels. Depending on the affected vessel type, these malformations are divided into capillary, venous, lymphatic, arteriovenous or combined

\footnotetext{
*Correspondence: laurence.boon@uclouvain.be

${ }^{1}$ Center for Vascular Anomalies, Division of Plastic Surgery, Cliniques

universitaires Saint Luc, University of Louvain, 10 avenue Hippocrate, B-1200

Brussels, Belgium

${ }^{10}$ Human Molecular Genetics, de Duve Institute, University of Louvain,

Brussels, Belgium

Full list of author information is available at the end of the article
}

malformations [1-3]. They are usually present at birth but can appear during childhood or adulthood [4].

Venous malformations (VM) often cause deformation, pain, chronic anaemia and important functional restraint. About $50 \%$ of VMs have associated coagulation abnormalities with high $\mathrm{D}$-dimer and normal-to-low fibrinogen levels. This localized intravascular coagulopathy is relatively specific for VM and is used as a diagnostic test [5-8].

Lymphatic malformations (LM) are micro- or macrocystic, or mixed, and can be localized or diffuse, as observed in generalized lymphatic anomalies (GLA). They 
can cause deformation, infiltration and compression of vital structures, similar to VM. They are often associated with oozing, bruizing and chronic infections [9].

Combined malformations also exist. Typical are the capillary-lymphatico-venous malformations with or without overgrowth of the affected limb (formerly known as Klippel-Trenaunay syndrome, KTS) and the complex vascular malformations (e.g. arterio-venous or venous malformations) seen in the PTEN hamartoma tumour syndrome (PHTS) $[10,11]$.

The diagnosis of a vascular malformation is usually based on history and physical examination. Further investigations include Doppler ultrasonography, MRI and D-dimer and fibrinogen level measurements to identify a venous component and/or to exclude a coagulation abnormality [12]. Sclerotherapy alone or in combination with surgical resection is the gold standard procedure for most slow-flow vascular malformations [13, 14]. These procedures are rarely curative in patients with extensive and infiltrating lesions. Thus, an important unmet medical need exists.

The tyrosine kinase receptor TIE2 and its ligands angiopoietin-1 and -2, play a key role in vascular maturation and stability through the Phosphatidylinositol-3-kinase (PI3K)/AKT/mammalian Target of Rapamycin (mTOR) signalling pathway. Up to $60 \%$ of VMs are due to somatic TIE2 mutations, resulting in ligand-independent activation of the receptor [15-20]. Another 20\% of VMs are due to somatic activating mutations of PIK3CA encoding for the p110 catalytic subunit of PI3K [21]. These mutations lead to a sustained activation of the PI3K/AKT/mTOR pathway, responsible for accumulation of endothelial cells due to reduced apoptosis and defective recruitment of vascular smooth muscle cells [15, 22-24], which results in the enlarged, convoluted venous channels. Recently, the first animal model of VM was developed through injection of TIE2-mutated human umbilical vein endothelial cells HUVECs subcutaneously into nude mice. In this model, sirolimus administration stopped the growth of VM-lesions [22]. Similarly, somatic/mosaic PIK3CA mutations are found in the majority of LM and complex malformations (KTS), underscoring mTOR activation as an interesting target for medical treatment of slow-flow vascular malformations [22].

Sirolimus, also known as rapamycin, is an allosteric inhibitor of mTOR. It is used in a number of medical disciplines, especially as an immunosuppressive drug to prevent organ rejection, as an anti-angiogenic medication on coated cardiologic stents and as a cytostatic agent in breast and renal cancer. Moreover, our pilot study and two previously reported trials showed efficacy in selected vascular malformations $[22,25,26]$. We now performed a monocentric prospective phase II clinical trial to evaluate sirolimus efficacy and safety for patients (children and adults) with extensive and/or complex slow-flow vascular malformations that were refractory to standard treatments.

\section{Methods \\ Patients}

Inclusion criteria included symptomatic slow-flow vascular malformations that were refractory to standard care, such as sclerotherapy and/or surgical resection. Chronic pain, functional restraint, recurrent infections (defined as $>3$ episodes/year), oozing, bleeding and/or coagulation abnormality were the symptoms considered for inclusion in the study.There was no age limitation. The eligible patients had to have adequate liver (bilirubin, ASAT, ALAT), medullar (neutrophils $\geq 1500 / \mathrm{mm}^{3}$, hemoglobin $\geq 8,0 \mathrm{mg} / \mathrm{dl}$ and platelets $\geq 50.000 / \mathrm{mm}^{3}$ ) and renal function (clearance $\geq$ $70 \mathrm{ml} / \mathrm{min} / 1.73 \mathrm{~m}^{2}$ ) with a Karnofsky performance status $\geq$ 50. If partial surgical resection was performed, the tissues were screened for presence of somatic TIE2 or PIK3CA mutations, as described [21].

Exclusion criteria included severe, concurrent and/or uncontrolled diseases (cardiopathy, diabetes, infection, HIV, hypertension...), concomitant CYP3A4 inhibitor/inducer intake, gastro-intestinal disorders that might modify sirolimus absorption, pregnancy and lactation for women. Patients could not have had a surgical resection and/or sclerotherapy within 4 weeks prior to study entry. Exclusion criteria also included previous use of an mTOR inhibitor.

\section{Study protocol and treatment}

This is a crossover trial using patient's long-term clinical, biological and radiological history before sirolimus treatment as control [27]. Pre-treatment analysis included D-dimer and fibrinogen level measurements, and MRI studies using T1-weighted imaging without gadolinium chelate injection, T2-weighted imaging with Fat Saturation and/or STIR sequences in two orthogonal planes.

Sirolimus was started with a dose of $0.8 \mathrm{mg} / \mathrm{m}^{2}$ body surface, twice-a-day, using liquid solutions for children under the age of 12 years, and with a single dose of $2 \mathrm{mg} /$ day, using a tablet, for older patients. All patients were seen every month for the first 3 months, then every 3 months in order to evaluate the signs and symptoms of the malformation, compliance and possible side-effects of the drug. After 1 week of treatment, sirolimus serum level was measured and daily sirolimus dose was adapted to reach a blood level between 10 to $15 \mathrm{ng} / \mathrm{ml}$. If the patient experienced grade 3-4 toxicities, sirolimus dose was decreased. Hemogram, liver and renal function, coagulation parameters and thyroid tests were monitored every 3 months.

Treatment was suspended in cases of severe toxicity, patient and/or parents who refused to continue, and patients who did not experience any benefit after 3 months 
of therapy. For all patients enrolled in this study, a follow-up is planned for 5 years.

The primary endpoint was efficacy and safety of sirolimus at 12 months. Efficacy of the medication was evaluated based on physical (clinical size, colour and consistency of the lesion), functional (organ dysfunction, mobility restraint, pain, bleeding, oozing, repetitive infections), biological (measurement of coagulation parameters) and radiological response, as well as on quality of life (QoL) questionnaire. Clinical examination and measurement of lesions were performed at each consultation. Evaluation of pain was based on visual analog scale (VAS) for adult and on the faces pain scale for children, both ranging from 0 (no pain) to 10 (excessive pain). Radiological evaluation was based on the comparison between the pre-study MRI and the MRI performed at one-year follow-up. Imaging analysis was completed by using the ITK-SNAP ${ }_{3-0}$ software from the DICOM source images, to obtain an objective quantification of the volume of the malformation [28, 29]. This program required a manual or semi-automatic contouring of the lesions on the MRI slices, which subsequently generated a 3-dimensional image and volume calculation. QoL was based on a questionnaire modified from Medical Outcomes Study 36-Item Short Form (MOS SF-36) for adults. Specific questionnaires from "Pediatric Quality of Life Inventory" (PEDSQL) were used for infants from age 5-7 years, 8-12 years and 13-18 years, and a corresponding questionnaire for their respective parents (www.pedsql.org). Moreover, a global self-evaluation percentage $(0 \%=$ no change to $100 \%=$ symptom free; improvement was considered as weak between 0 and $20 \%$, moderate between 20 and $50 \%$ and strong when superior to $50 \%$ ) was recorded for each patient and/or parents at each consultation. Coagulation changes (D-dimer and fibrinogen levels) were also recorded. Adverse events were assessed according to the Common Terminology Criteria for Adverse Events (CTCAE) version 3.0.

Response was defined as follows:

- Complete response (CR), defined as a complete disappearance of the lesion (clinical and/or radiological), of the symptoms and normalisation of QoL.

- Partial response (PR), defined as a reduction of $\geq 20 \%$ in size of the vascular lesion (clinical and/or radiological), improvement of symptoms and/or QoL.

- Absence of response (AR), defined as a progressive disease (increase in size, symptoms and decreased QoL) or disease stability (reduction of $<20 \%$ in size and no improvement of symptoms and QoL).

\section{Statistical analysis}

Statistical analyses were performed using the SPSS version 24.0 [30]. Paired sample t-tests were applied with a significance threshold of 0.05 .

\section{Results}

Nineteen patients, 12 females and 7 males, aged from 3 to 64 years (median: 15 years) were enrolled between January 2011 and January 2015. Six patients had a LM, two had a generalized lymphatic anomaly (GLA), seven had a VM, one had a capillary venous malformation (CVM), two had KTS and one had PHTS. Characteristics of patients are described in Table 1.

All but one patient had previously been treated with several sequences of sclerotherapies and/or surgical resection. All had severe symptoms varying from esthetic deformation $(n=15)$, chronic pain (VAS 3-10) refractory to conventional medications $(n=13)$, organ or mobility dysfunction $(n=17)$, recurrent infections $(n=10)$, bleeding $(n=4)$, and/or oozing $(n=4)$. All patients had a poor QoL. Of the 11 patients with a venous component, 10 (90\%) had elevated D-dimer levels and $1 \mathrm{VM}$ (\#9) had low fibrinogen levels before sirolimus initiation.

Sixteen patients received sirolimus for at least 12 months; two stopped earlier because of grade 3 mucositis and one spontaneously decided to stop the study. Thirteen patients are still on treatment, with a follow-up ranging from 15 to 48 months.

\section{Efficacy}

Sixteen patients were evaluated for efficacy after 1 year of sirolimus treatment (Table 2). A partial response was observed in all patients $(n=16 / 16)$. There was no complete response.

\section{Lesional change}

In patients with visible vascular malformations sirolimus resulted in a noticeable improvement in appearance compared to previous photographs in 11 patients at 1 year time-point (Figs. 1 and 2) resulting in an clinical response rate of $78 \%$. This improvement appeared within 3 months from the start of sirolimus in all of these patients and persisted at 6- and 12-month evaluation points. No clinical disappearance of the lesion was observed but the volume reduction induced by sirolimus allowed sclerotherapy for patient \#2 and surgical resection for patient \#17. The patient who stopped sirolimus after 2 months because of grade 3 mucositis (\#11) did not have any physical improvement during this short period.

\section{Functional change}

All patients experienced improvement in mobility or organ function, reduction of pain, bleeding or oozing, or reduction or cessation of infections, resulting in a $100 \%$ general improvement rate. These appeared within 3 months from the start of sirolimus and were maintained. Similarly, patient \#11 (with a limited 2-month-treatment) experienced improvement in mobility. 


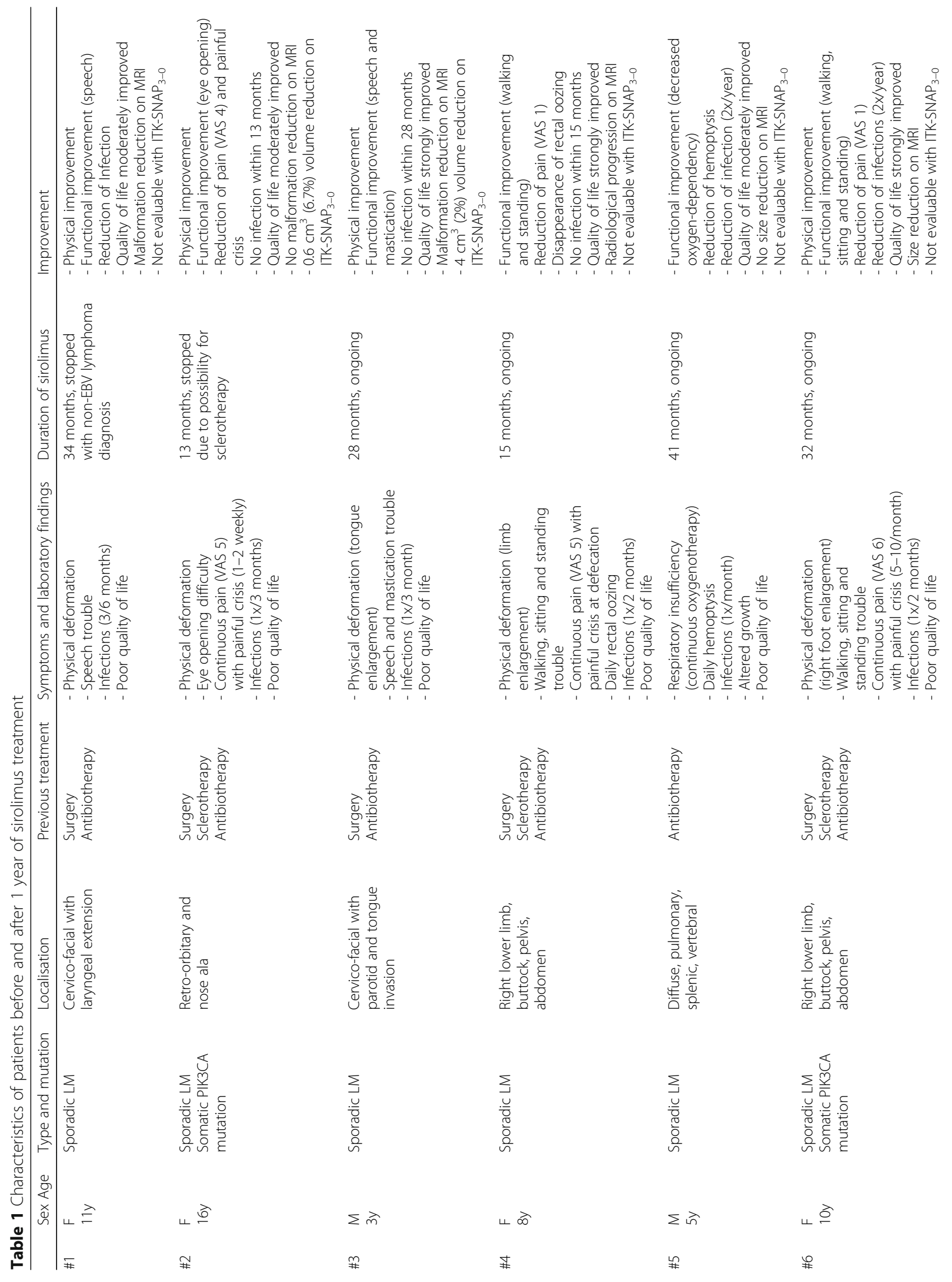









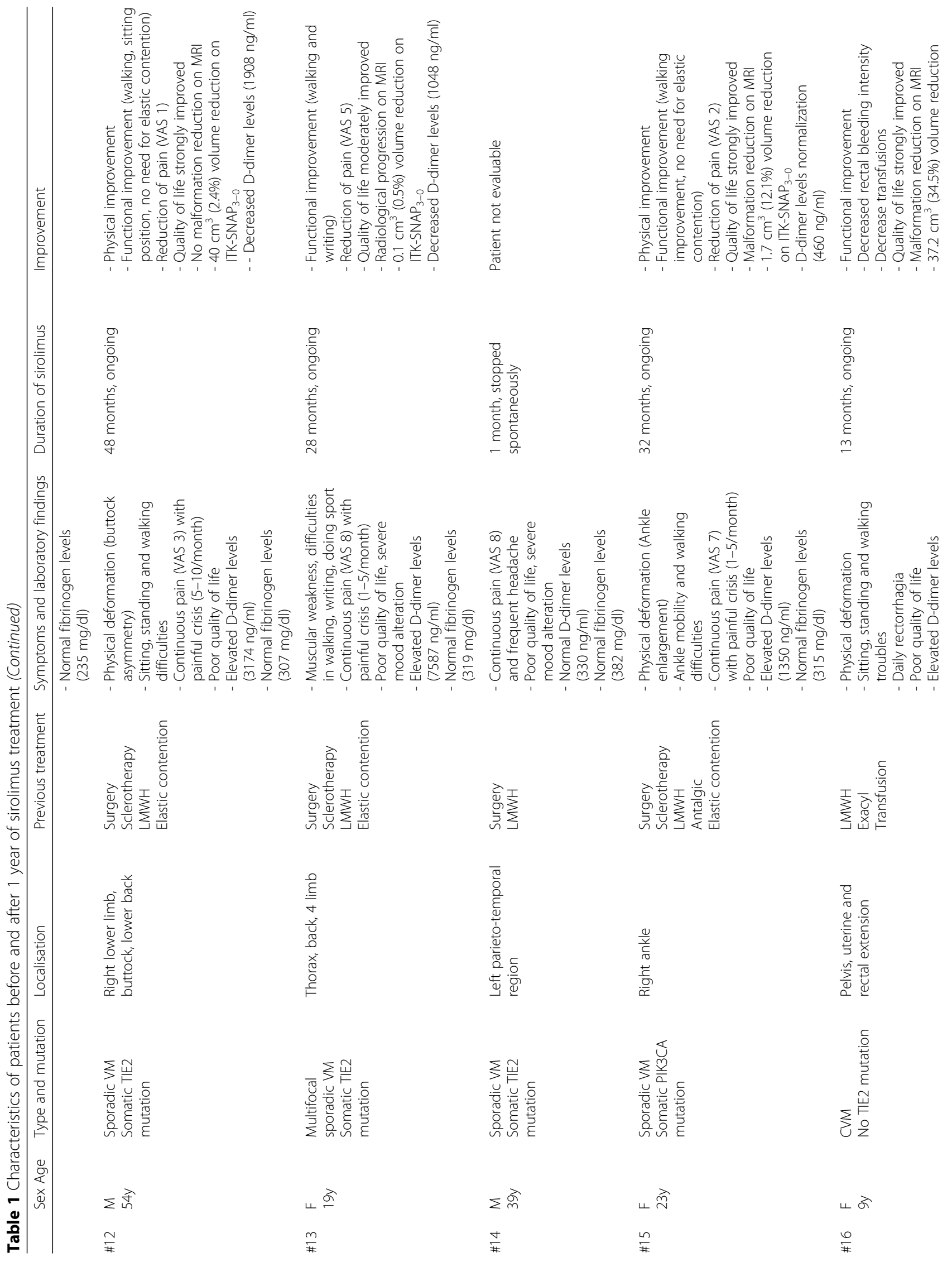




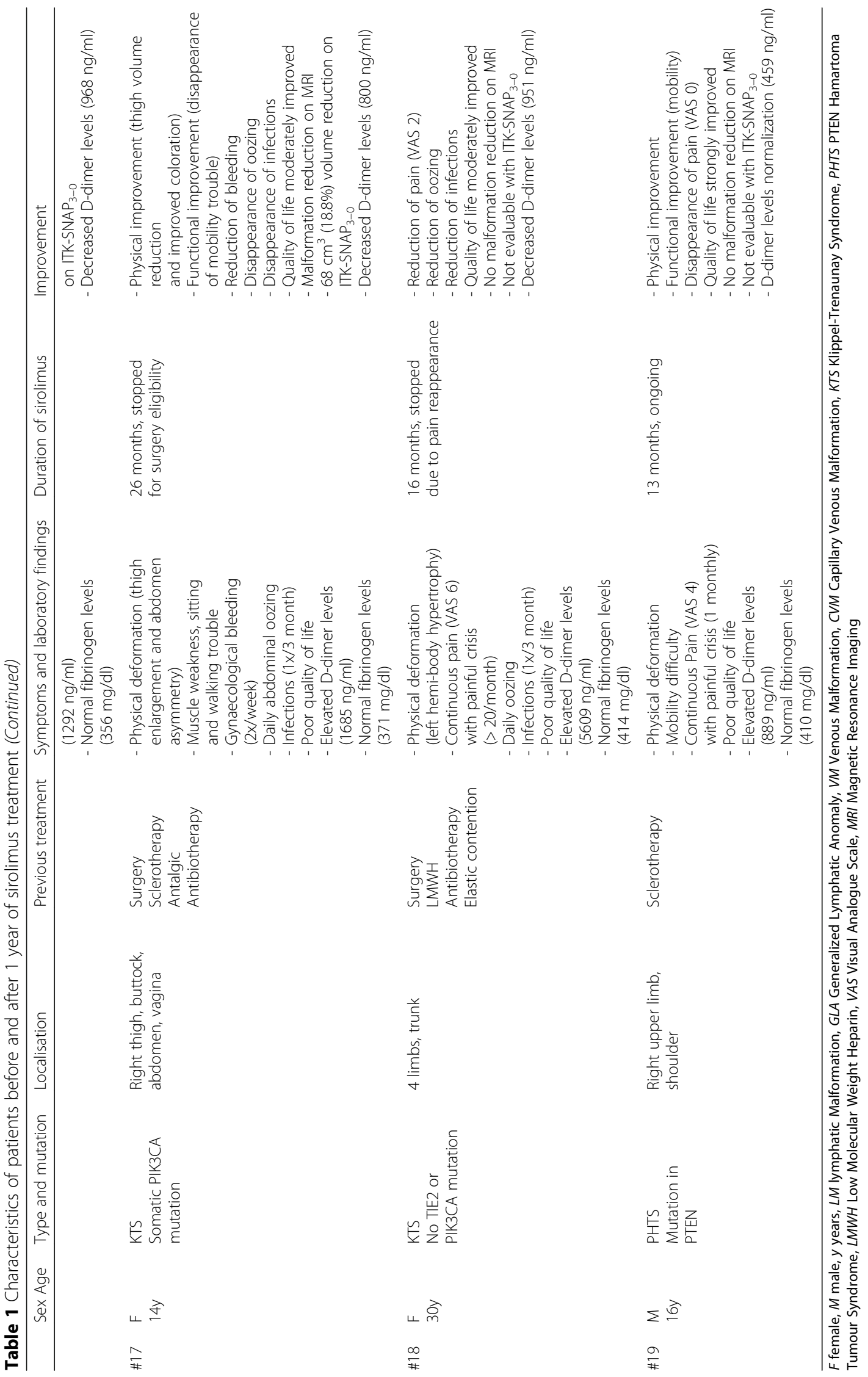


Table 2 Efficacy after 1 year of sirolimus treatment

\begin{tabular}{|c|c|c|c|c|c|c|c|}
\hline $\begin{array}{l}\text { Efficacy at } 12 \text { months FU } \\
(n=16)\end{array}$ & $\operatorname{LM}(n=6)$ & $\mathrm{GLA}(n=2)$ & $\mathrm{VM}(n=4)$ & $\operatorname{CVM}(n=1)$ & KTS $(n=2)$ & PHTS $(n=1)$ & Total \\
\hline Physical examination $(n=14)$ & $n=4 / 5(80 \%)$ & $n=2 / 2(100 \%)$ & $n=3 / 3(100 \%)$ & $n=0$ & $n=1 / 2(50 \%)$ & $n=1 / 1(100 \%)$ & $n=11 / 14(78 \%)$ \\
\hline $\begin{array}{l}\text { Organ or mobility dysfunction } \\
(n=15)\end{array}$ & $n=6 / 6(100 \%)$ & $n=2 / 2(100 \%)$ & $n=4 / 4(100 \%)$ & $n=1 / 1(100 \%)$ & $n=1 / 1(100 \%)$ & $n=1 / 1(100 \%)$ & $n=15 / 15(100 \%)$ \\
\hline Pain $(n=10)$ & $n=3 / 3(100 \%)$ & $n=1 / 1(100 \%)$ & $n=4 / 4(100 \%)$ & $n=0$ & $n=1 / 1(100 \%)$ & $n=1 / 1(100 \%)$ & $n=10 / 10(100 \%)$ \\
\hline Bleeding $(n=4)$ & $n=1 / 1(100 \%)$ & $n=0$ & $n=1 / 1(100 \%)$ & $n=1 / 1(100 \%)$ & $n=1 / 1(100 \%)$ & $n=0$ & $n=4 / 4(100 \%)$ \\
\hline Oozing $(n=4)$ & $n=1 / 1(100 \%)$ & $n=1 / 1(100 \%)$ & $n=0$ & $n=0$ & $n=2 / 2(100 \%)$ & $n=0$ & $n=4 / 4(100 \%)$ \\
\hline Repetitive infections ( $n=10$ ) & $n=6 / 6(100 \%)$ & $n=2 / 2(100 \%)$ & $n=0$ & $n=0$ & $n=2 / 2(100 \%)$ & $n=0$ & $n=10 / 10(100 \%)$ \\
\hline \multicolumn{8}{|l|}{ Quality of life $(n=16)$} \\
\hline - No amelioration & $n=0$ & $n=0$ & $n=0$ & $n=0$ & $n=0$ & $n=0$ & $n=0(0 \%)$ \\
\hline - Moderate amelioration & $n=3 / 6(50 \%)$ & $n=0$ & $N=1 / 4(25 \%)$ & $n=0$ & $n=2 / 2(100 \%)$ & $n=0$ & $n=6 / 16(37.5 \%)$ \\
\hline - Strong amelioration & $n=3 / 6(50 \%)$ & $n=2 / 2(100 \%)$ & $n=3 / 4(75 \%)$ & $n=1 / 1(100 \%)$ & $n=0$ & $n=1 / 1(100 \%)$ & $n=10 / 16(62.5 \%)$ \\
\hline Reduced coagulopathy $(n=8)$ & $\mathrm{n} / \mathrm{a}$ & $\mathrm{n} / \mathrm{a}$ & $n=4 / 4(100 \%)$ & $n=1 / 1(100 \%)$ & $n=2 / 2(100 \%)$ & $N=1 / 1(100 \%)$ & $n=8 / 8(100 \%)$ \\
\hline \multicolumn{8}{|l|}{ MRI (T1,T2 Fat Sat,STIR) $(n=16)$} \\
\hline - Progression & $n=1 / 6(17 \%)$ & $n=1 / 2(50 \%)$ & $n=1 / 4(25 \%)$ & $n=0$ & $n=0$ & $n=0$ & $n=3 / 16(19 \%)$ \\
\hline - Status quo & $n=2 / 6(33 \%)$ & $n=0$ & $n=2 / 4(50 \%)$ & $n=0$ & $n=1 / 2(50 \%)$ & $n=1 / 1(100 \%)$ & $n=6 / 16(37 \%)$ \\
\hline - Amelioration & $n=3 / 6(50 \%)$ & $n=1 / 2(50 \%)$ & $n=1 / 4(25 \%)$ & $n=1 / 1(100 \%)$ & $n=1 / 2(50 \%)$ & $n=0$ & $n=7 / 16(44 \%)$ \\
\hline \multicolumn{8}{|l|}{ ITK-SNAP ${ }_{3-0}(n=9)$} \\
\hline - Volume augmentation & $n=0$ & $n=0$ & $n=0$ & $n=0$ & $n=0$ & $n=0$ & $n=0 / 9(0 \%)$ \\
\hline - No volume modification & $n=0$ & $n=0$ & $n=1 / 4(25 \%)$ & $n=0$ & $n=0$ & $n=0$ & $n=1 / 9(11 \%)$ \\
\hline - Volume reduction & $n=2 / 2(100 \%)$ & $n=1 / 1(100 \%)$ & $n=3 / 4(75 \%)$ & $n=1 / 1(100 \%)$ & $n=1 / 1(100 \%)$ & $n=0$ & $n=8 / 9(89 \%)$ \\
\hline
\end{tabular}

FU Follow-Up, LM Lymphatic Malformation, GLA Generalized Lymphatic Anomaly, VM Venous Malformation, CVM Capillary Venous Malformation, KTS KlippelTrenaunay Syndrome, PHTS PTEN Hamartoma Tumour Syndrome, $n / a$ not applicable

Pain improved in all evaluable patients $(n=10)$ (Fig. 3). These patients suffered from chronic pain (VAS ranging from 3 to 10) with frequent painful crises commonly reaching at least VAS 8 . Median VAS score for baseline continuous pain decreased from 6 to 2 at 3,6 and 12 months follow-up and this improvement persisted at 6 and 12 months follow-up. The median frequency of painful crises decreased from $5 /$ month to $1 /$ month $(p=0.001)$. Interestingly, pain recurred within $72 \mathrm{~h}$ in two patients, 1 with LM (\#6) and 1 with VM (\#9), after sirolimus cessation for grade 2 headache and fatigue, respectively, and reduced again rapidly after sirolimus reintroduction. For one patient with extensive lower limb VM (\#12), pain disappeared completely after 2 weeks of treatment but reappeared after 6 months despite correct sirolimus blood level and an increased dosage (3 mg/day). After a 2-month therapy-gap, sirolimus reintroduction reduced pain again. Patient \#11 (with a limited 2-month-treatment) also experienced pain reduction.

Bleeding was a common sign in four patients. It reduced significantly in three patients (\#5, \#16, \#17) and stopped completely in one patient (\#9). After a few months, patients

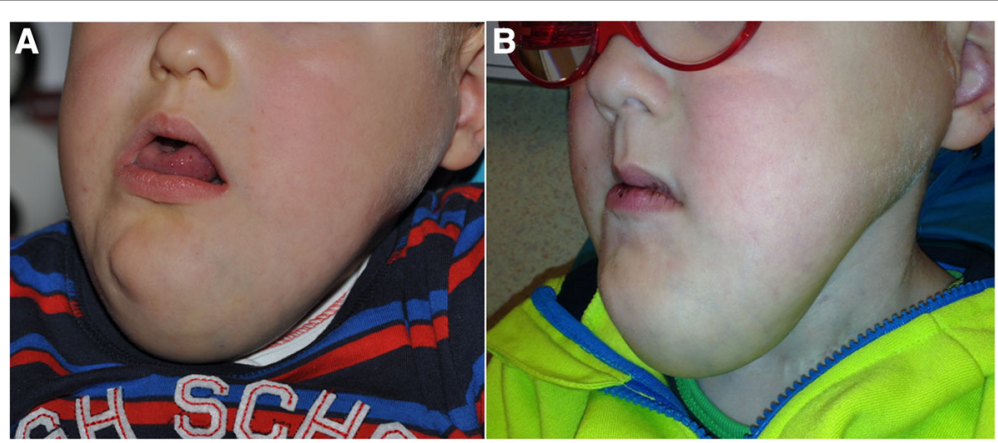

Fig. 1 Patient \#3 with a cervico-facial microcystic LM before initiation of sirolimus (a) and after 12 months of treatment (b) 


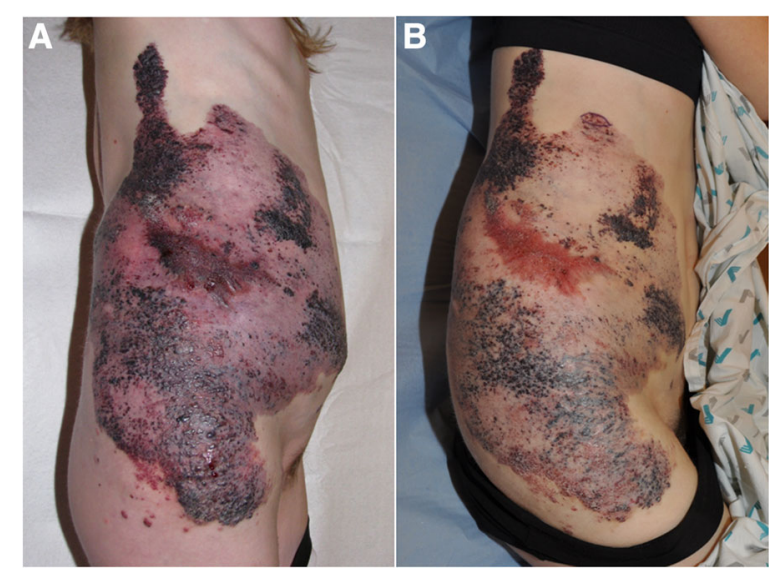

Fig. 2 Patient \#17 with a capillaro-lymphatico-venous malformation with hypertrophy (Klippel-Trenaunay syndrome) before initiation of sirolimus (a) and after 6 months of treatment (b)

\#9 and \#16 stopped the treatment during 2 weeks due to grade 2 fatigue, and bleeding resurged rapidly (in less than $72 \mathrm{~h}$ ). Sirolimus reintroduction stopped the bleeding in less than $48 \mathrm{~h}$ in both patients.

Infections and oozing also improved in all patients who frequently experienced them prior to treatment. Median frequency of infections per 6 months decreased from 3 to 1 . The four patients with oozing (\#4, \#8, \#17, \#18) experienced a rapid reduction in intensity and frequency with sirolimus.

\section{Quality of life}

After 1 year of sirolimus treatment, QoL improved in all patients $(n=16 / 16)$. Already after 3 months of treatment, moderate $(20-50 \%)$ or strong (>50\%) QoL improvement was seen in 6 and 10 patients, respectively. This improvement continued at 6 and 12 months time-points for all patients. Patient \#12 (see above) who had a strong initial improvement at 3 months, showed a decrease at 6 months due to pain resurgence, despite continuation and a dose-increase of sirolimus. After 2-month treatment arrest and sirolimus reintroduction, QoL improved again. Interestingly, patient \#11 who stopped sirolimus after 2 months because of grade 3 mucositis, presented a strong QoL improvement during this period.

\section{Coagulopathy}

Sirolimus decreased coagulation abnormalities. Out of the 11 patients with a venous component, 8 reached 12 months of treatment (all had pre-treatment D-dimer elevations). D-dimer levels decreased in all patients at 3 months and this reduction persisted at 12 months $(p=0.012)$ (Fig. 4). In two patients (\#9, \#12), D-dimer levels showed a temporary fluctuation that was correlated with resurgence of symptoms.

\section{Radiological aspect}

Among the 16 patients radiologically evaluated at 12 months of treatment, T2-MRI-weighted sequences showed a size reduction in 7 of them (43.7\%): three LM, one GLA, one VM, one CVM and one KTS. Despite clinical improvement, radiological progression of their malformation was observed in three patients (18.7\%): one LM, one GLA and one VM. On ITK-SNAP I-0 $_{3-0}$ evaluation, eight patients $(88.9 \%)$ showed reduction of their malformation (two LM, one GLA, three VM, one CVM, and one KTS) (Fig. 5). Only patient \#13 did not present significant volume reduction (reduction only $\left.0.1 \mathrm{~cm}^{3}(0.5 \%)\right)$. None of the nine patients evaluated with the ITK-SNAP segmentation program presented an

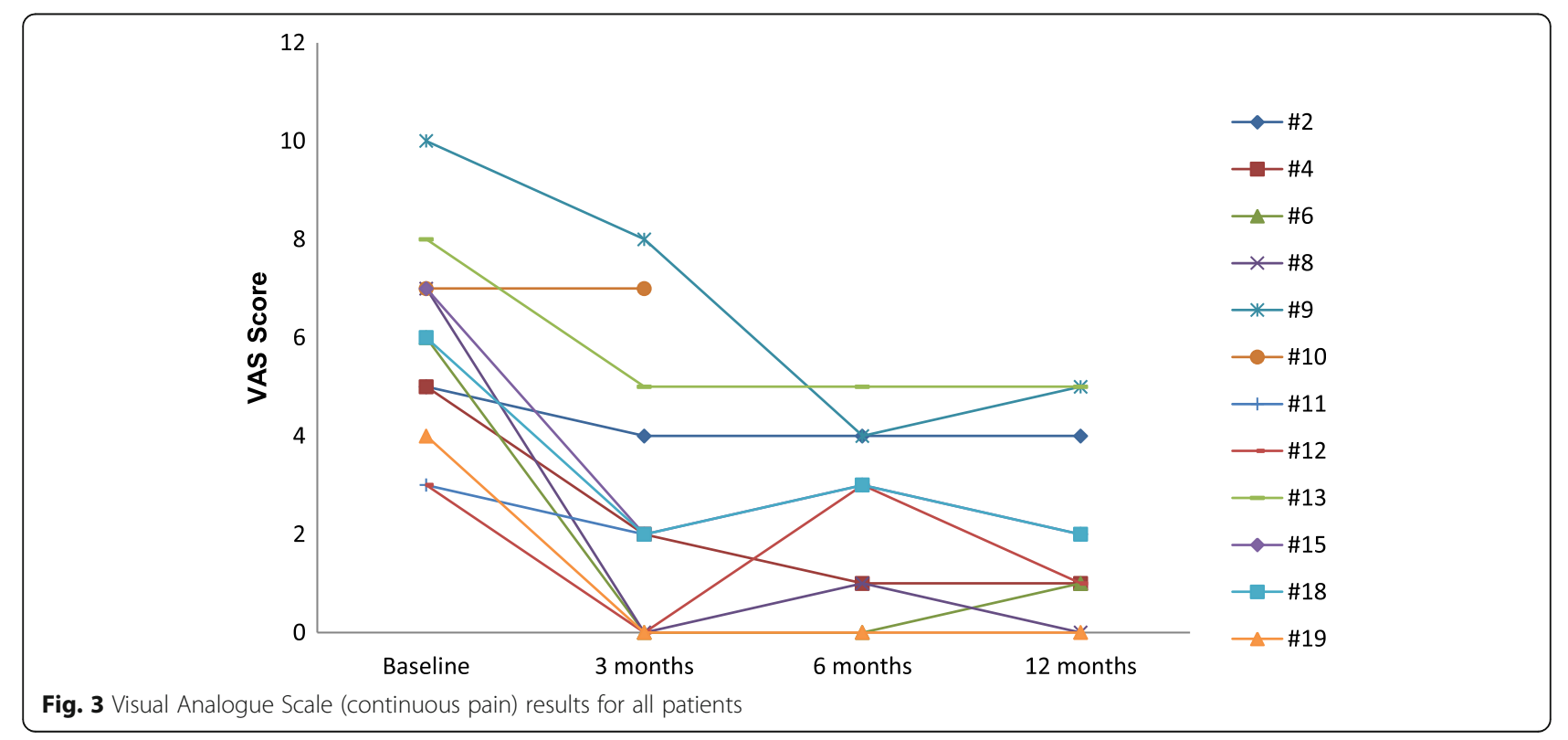




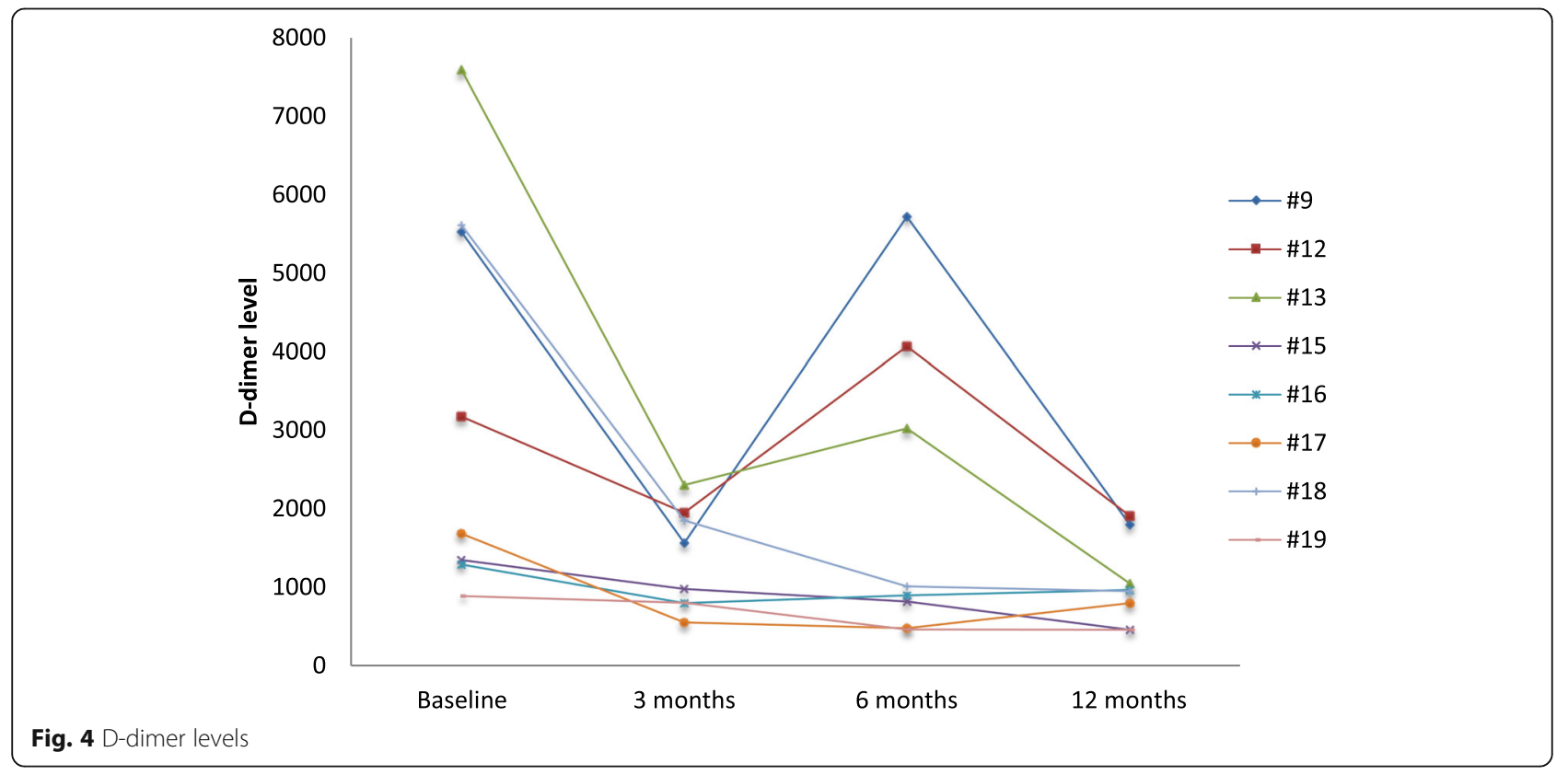

augmentation of the malformation volume. Seven patients (43.7\%) had to be excluded from this quantitative evaluation because of very infiltrative and/or multifocal disease compromising an adequate and reliable contouring of the lesions.

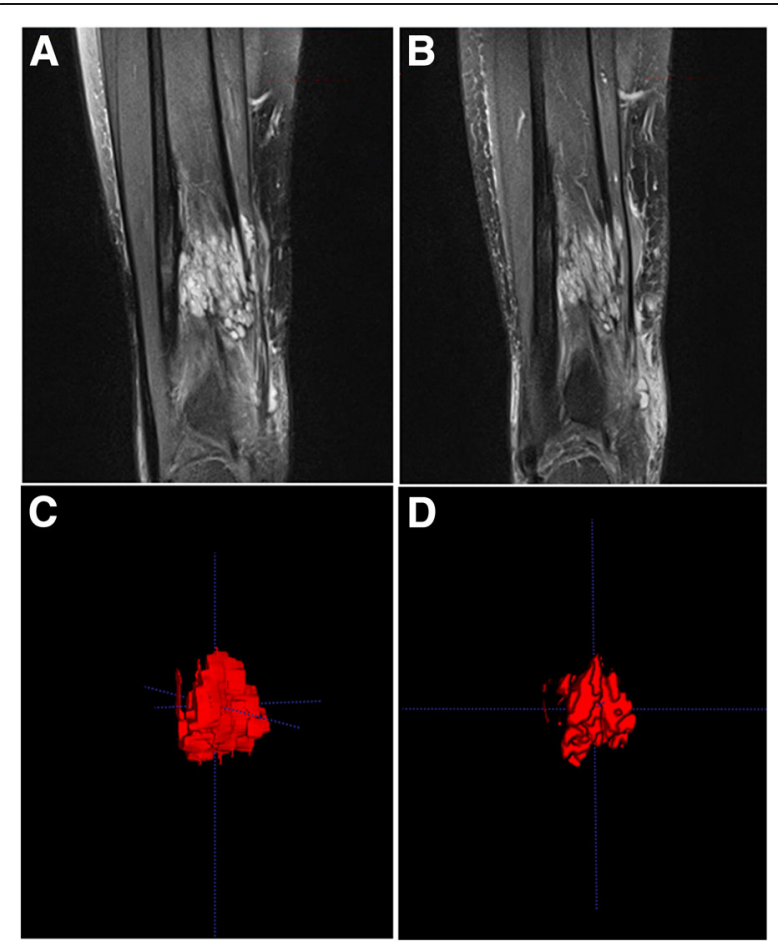

Fig. 5 Classical MRI sequences and 3D-volumes of the malformation (patient \#15) before initiation of sirolimus $(\mathbf{a}, \mathbf{c})$ and after 12 months of treatment $(\mathbf{b}, \mathbf{d})$. Notice volume reduction from $14 \mathrm{~cm}^{3}$ to $12,3 \mathrm{~cm}^{3}$

\section{Safety}

Sirolimus was well tolerated (Table 3): headache, skin rash, mucositis, fatigue and diarrhea were the most frequent grade 1-2 adverse events. All were easily manageable with symptomatic treatment or temporary arrest. Three patients stopped sirolimus for a few days due to grade 2 headache (\#6) or grade 2 fatigue (\#9, \#16).

Mucositis was the most common grade 3 adverse event and led to definitive discontinuation of sirolimus in $2 \mathrm{pa}-$ tients (\#10, \#11) despite dose adjustment. One 64-year-old patient, with previous history of basal celle carcinomas, had a recurrence of basal cell carcinoma after 1 year of treatment (\#9) and was cured by surgical resection without sirolimus interruption. One patient was diagnosed with diffuse large B-cell lymphoma 34 months after treatment initiation (\#1). This cancer was considered not to be related to sirolimus medication as it was not an EBV lymphoma.

\section{Discussion}

This prospective phase II study confirms the overall efficacy and safety of sirolimus in patients with refractory-to-standard-care slow-flow vascular malformations. Nineteen patients were included in this trial, representing an important number of these severe cases. All our enrolled patients were highly symptomatic, had a poor QoL and had failed to respond to previous therapies, including surgery, sclerotherapy and various medications. Thus, their lesional areas contained scarred tissues, not only nascent malformation. Yet, sirolimus was clearly efficacious.

Sirolimus was highly effective in VM, LM and combined lesions, and resulted in a partial response in all patients, reducing symptoms and increasing QoL. This was indirectly 
Table 3 Adverse events (CTCAE version 3.0)

\begin{tabular}{lll}
\hline Adverse events & $\begin{array}{l}\text { Grade 1-2 } \\
\mathrm{n}(\%)\end{array}$ & $\begin{array}{l}\text { Grade 3-4 } \\
\mathrm{n}(\%)\end{array}$ \\
\hline Conjunctiva & $1(5.3 \%)$ & 0 \\
Pneumonitis/pulmonary infiltrates & $1(5.3 \%)$ & 0 \\
Neuropathy & $1(5.3 \%)$ & 0 \\
Skin cancer (basal cell carcinoma) & 0 & $1(5.3 \%)$ \\
Lymphoma & 0 & $1(5.3 \%)$ \\
Anemia & 0 & 0 \\
Thrombocytopenia & $1(5.3 \%)$ & 0 \\
Leucopenia & 0 & 0 \\
Hypercholesterolemia/hyperglycemia & 0 & 0 \\
Headache & $11(57.9 \%)$ & 0 \\
Arterial hypertension & $1(5.3 \%)$ & 0 \\
Diarrhea & $7(36.9 \%)$ & 0 \\
Nausea/vomiting & $5(26.4 \%)$ & 0 \\
Mucositis/stomatitis & $7(36.9 \%)$ & $2(10.6 \%)$ \\
Abnormal liver function tests & 0 & 0 \\
Rash & $7(36.9 \%)$ & 0 \\
Arthralgia & $1(5.3 \%)$ & 0 \\
Flu-like syndrome & $6(31.6 \%)$ & 0 \\
Fatigue & $9(47.4 \%)$ & 0 \\
Wound healing & $2(10.6 \%)$ & 0 \\
Weight loss & $3(15.8 \%)$ & 0 \\
Insomnia & $4(21.1 \%)$ & 0 \\
\hline
\end{tabular}

confirmed by the fact that the majority of patients decided to continue sirolimus treatment even after study end-point due to the significant improvement. Our study also confirmed the reported data that sirolimus does not cure patients with vascular anomalies [22, 25, 26, 31].

The efficacy of sirolimus on pain, bleeding and oozing appeared within the first 3 months. Interestingly, the temporary arrest of sirolimus in three patients was associated with a rapid resurgence of pain and/or bleeding, and its reintroduction induced a reversibility. This impressive rapidity of action urges to consider sirolimus in life-threatening vascular malformations. Furthermore, sirolimus allowed interventional procedures that were initially considered unfeasible to be performed in two patients, suggesting that sirolimus could play a role as a pre-treatment before radical and curative interventional procedures of large complicated lesions. As most patients in this study had responded by 6 months, such a pre-treament period could be envisioned. Future clinical trials should be performed to evaluate efficacy of sirolimus on nascent malformations free of scaring.

Sirolimus was well tolerated, both in children and in adults. Adverse events were mostly grade 1 and 2, and easily manageable with symptomatic treatment or temporary arrest. Mucositis was the most common grade 3 adverse event. A young patient presented lymphoma after 34 months of treatment. Despite the fact that it is not possible to completely exclude an indirect role of sirolimus due to its immonusuppressive effect, we considered, after a multidisciplinary discussion, that the lymphoma was not directly caused by the medication since the lymphoma was not of EBV-type. Similarly, a 64-year old patient with a basal cell carcinoma after 1 year of treatment, had a previous history of basal cell carcinomas. Thus, it was not considered to be associated with the sirolimus treatment. Despite absence of direct correlation between sirolimus and these adverse events, follow-up of patients treated with mTOR inhibitor is mandatory and should include an annual dermatological control, and a haematological control (hemogram, liver, thyroid and renal function) every 3-6 months.

D-dimer level could appear as a potential predictive biomarker for efficacy, since in our study D-dimer levels were associated with sirolimus efficacy and symptomatology. Levels decreased in all of the evaluated patients with a venous component. Furthermore, in two patients $(\# 9, \# 12)$ with initial sirolimus efficacy, symptoms reappeared and were associated with a re-increase in D-dimer levels. Further studies should evaluate early evolution of D-dimers in order to identify patients who mostly benefit from mTOR inhibition.

Despite largely favourable clinical responses, qualitative interpretation of MRI studies routinely used to evaluate clinical progression of vascular malformations, detected regression of lesions only in a minority of patients. The more sensitive ITK-SNAP ${ }_{3-0}$ evaluation unravelled a slightly higher response rate of a 2 -to-34\% reduction of malformation volume in 8 out of 9 patients at 12 months. This underscores the use of clinical examination, QoL questionnaire and biomarkers as the best tools to evaluate clinical response.

Our study is limited by the number of patients enrolled extensive, refractory-to-standard-care VM, LM and complex vascular lesions are rare - and the heterogeneity of the malformations. Yet, they have a common pathophysiological basis: activation of the PIK3/AKT/mTOR signalling pathway, the target of sirolimus treatment. The results of this phase II study underscore the efficacy of sirolimus in these varied lesions.

Follow-up reached for some patients 48 months. Although too short to confirm long-term efficacy and safety of sirolimus, it gives a basis for such evaluation. As patients experienced clear amelioration of their quality of life, long-term treatment may become a rule. The best tools to measure efficacy thus also seem to be QoL questionnaire and pain with VAS (both with a subjective component). Both may though have confounding effects as 
many patients have been symptomatic since they were born. Initiation of sirolimus treatment often makes them realize the level of chronic pain they were used to. In patients with a venous component, biomarkers such as D-dimer levels are very helpful to monitor efficacy.

All these results are in concordance with our original report on VM and the few reports on LM and/or VM $[22,25,26,31]$. Notably, Adams and coworkers performed a prospective two-center study with similar response criteria and results [31]. The repeated demonstration of efficacy urges larger phase III trials to be conducted, with enlargement of enrolment criteria.

\section{Conclusion}

Our study confirms that sirolimus is an effective therapeutic option for symptomatic patients with extensive LM, VM and/or complex malformation for which surgery and sclerotherapy do not provide a satisfactory solution. The quality of life is enhanced and pain is reduced. Indications may need to be enlarged, and studies performed on nascent lesions.

\section{Acknowledgements}

We thank Dr. Denise Adams for sharing her sirolimus protocol and for her expertise in treating patients with lymphatic anomalies.

\section{Funding}

These studies were partially funded by the Fonds de la Recherche

Scientifique - FNRS; by grant number T.0146.16.

\section{Availability of data and materials}

The datasets used and analysed during the current study are available from the corresponding author on reasonable request.

\section{Authors' contributions}

$J H, E S, M V, L B$ made substantial contributions to conception and design and $J H, E S$ SoD, AV, SS, CH, CC, PC, FH, MV, LB to acquisition of data. JH, ES, StD, $M V$, LB made contributions to analysis and interpretation of data and have been involved in drafting the manuscript and revising it critically for important intellectual content. All authors have given final approval of the version to be published.

\section{Ethics approval and consent to participate}

This study (NCT01811667; EudraCT 2012-001262-15) was approved by the Ethics Committee of the Cliniques universitaires Saint-Luc, Brussels, Belgium. Each patient or patient's parent signed an informed consent after receiving a summary explaining the procedure of the study. The trial was also registered at clinicaltrials.gov under the name VASCA-LM.

\section{Consent for publication}

Each patient or patient's parent signed a consent for publication.

\section{Competing interests}

The authors declare that they have no competing interests.

\section{Publisher's Note}

Springer Nature remains neutral with regard to jurisdictional claims in published maps and institutional affiliations.

\section{Author details}

${ }^{1}$ Center for Vascular Anomalies, Division of Plastic Surgery, Cliniques universitaires Saint Luc, University of Louvain, 10 avenue Hippocrate, B-1200 Brussels, Belgium. ${ }^{2}$ Center for Vascular Anomalies, Institut Roi Albert II, Department of Medical Oncology, Cliniques universitaires Saint Luc,
University of Louvain, Brussels, Belgium. ${ }^{3}$ Department of Pediatric Hemato-oncology, Cliniques universitaires Saint Luc, University of Louvain, Brussels, Belgium. ${ }^{4}$ Center for Vascular Anomalies, Department of Pediatric Hemato-oncology, Cliniques universitaires Saint Luc, University of Louvain, Brussels, Belgium. ${ }^{5}$ Center for Vascular Anomalies, Department of Head and Neck Surgery, Cliniques universitaires Saint-Luc, University of Louvain, Brussels, Belgium. 'Department of Pediatric Hemato-oncology, CHR Citadelle, Liège, Belgium. 'Department of Pediatric Cardiology, CHRU Lille, Lille, France. ${ }^{8}$ Division of Pediatric Radiology, Cliniques universitaires Saint-Luc, University of Louvain, Brussels, Belgium. ${ }^{9}$ Division of Interventional Radiology, Cliniques universitaires Saint-Luc, University of Louvain, Brussels, Belgium. ${ }^{10}$ Human Molecular Genetics, de Duve Institute, University of Louvain, Brussels, Belgium.

Received: 19 June 2018 Accepted: 11 October 2018

Published online: 29 October 2018

\section{References}

1. Wassef M, Blei F, Adams D, Alomari A, Baselga E, Berenstein A, et al. ISSVA board and scientific committee. Vascular anomalies classification: recommendations from the International Society for the Study of vascular anomalies. Pediatrics. 2015;136:203-14.

2. Boon LM, Ballieux F, Vikkula M. Pathogenesis of vascular anomalies. Clin Plast Surg. 2011;38:7-19.

3. Mulliken JB, Glowacki J. Hemangiomas and vascular malformations in infants and children: a classification based on endothelial characteristics. Plast Reconstr Surg. 1982;69:412-22.

4. Greene AK, Liu AS, Mulliken JB, Chalace K, Fishman SJ. Vascular anomalies in 5621 patients: guidelines for referral. J Pediatr Surg. 2011;46:1784-9.

5. Vikkula M, Boon LM, Carraway KL, Calvert JT, Diamonti AJ, Goumnerov B, et al. Vascular dysmorphogenesis caused by an activating mutation in the receptor tyrosine kinase TIE2. Cell. 1996;87:1181-90.

6. Dompmartin A, Vikkula M, Boon LM. Venous malformation: update on aetiopathogenesis, diagnosis and management. Phlebology. 2010;25:224-35.

7. Dompmartin A, Acher A, Thibon P, et al. Association of localized intravascular coagulopathy with venous malformations. Arch Dermatol. 2008;144:873-7.

8. Dompmartin A, Bailleux F, Thibon P, Lequerrec A, Hermans C, Clapuyt P, et al. Elevated D-dimer level is diagnostic for venous malformations. Arch Dermatol. 2009;145:1239-44

9. Boon LM, Vikkula M. Vascular malformations. In: Wolff K, Goldsmith LA, Katz SI, Gilchrest BA, Paller AS, Leffell DJ, editors. Fitzpatrick's dermatology in general medicine. 8th ed. New York: McGraw-Hill Professional Publishing; 2012. p. 2076-94.

10. Oduber CE, van der Horst CM, Hennekam RC. Klippel-Trenaunay syndrome: diagnostic criteria and hypothesis on etiology. Ann Plast Surg. 2008;60:217-23.

11. Pilarski R, Stephens JA, Noss R, Fisher JL, Prior TW. Predicting PTEN mutations: an evaluation of Cowden syndrome and Bannayan-RileyRuvalcaba syndrome clinical features. J Med Genet. 2011;48:505-12.

12. Wassef M, Vanwijck R, Clapuyt P, Boon LM, Magalon G. Vascular tumours and malformations, classification, Pathology and imaging. Ann Chir Plast Esthet. 2006:51:263-81.

13. Cahill AM, Nijs EL. Pediatric vascular malformations: pathophysiology, diagnosis, and the role of interventional radiology. Cardiovasc Intervent Radiol. 2011:34:691-704.

14. Boon LM, Vanwijck R. Medical and surgical treatment of venous malformations. Ann Chir Plast Esthet. 2006;51:403-11.

15. Uebelhoer M, Nätynki M, Kangas J, Mendola A, Nguyen HL, Soblet J, et al. Venous malformation causative TIE2 mutations mediate an AKT dependent decrease in PDGF- $\beta$. Hum Mol Genet. 2013;22:3438-48.

16. Soblet J, Kangas J, Nätynki M, Mendola A, Helaers R, Uebelhoer M, et al. Blue Rubber Bleb Nevus (BRBN) syndrome is caused by somatic TEK (TIE2) mutations. J Invest Dermatol. 2017;137:207-16.

17. Limaye N, Wouters V, Uebelhoer M, Tuominen M, Wirkkala R, Mulliken JB, et al. Somatic mutations in angiopoietin receptor gene TEK cause solitary and multiple sporadic venous malformations. Nat Genet. 2009;41:118-24.

18. Soblet J, Limaye N, Uebelhoer M, Boon LM, Vikkula M. Variable somatic TIE2 mutations in half of sporadic venous malformations. Mol Syndromol. 2013;4:179-83.

19. Wouters $\mathrm{V}$, Limaye $\mathrm{N}$, Uebelhoer $\mathrm{M}$, Irrthum $\mathrm{A}$, Boon LM, Mulliken JB, et al. Hereditary cutaneomucosal venous malformations are caused by TIE2 
mutations with widely variable hyper-phosphorylating effects. Eur J Hum Genet. 2010;18:414-20.

20. Calvert JT, Riney TJ, Kontos CD, Cha EH, Prieto VG, Shea CR, et al. Allelic and locus heterogeneity in inherited venous malformations. Hum Mol Genet. 1999:8:1279-89.

21. Limaye N, Kangas J, Mendola A, Godfraind C, Schlögel MJ, Helaers R, et al. Somatic activating PIK3CA mutations cause venous malformation. Am J Hum Genet. 2015;97:914-21.

22. Boscolo E, Limaye N, Huang L, Kang KT, Soblet J, Uebelhoer M, et al. Rapamycin improves TIE2-mutated venous malformation in murine model and human subjects. J Clin Invest. 2015;125:3491-504.

23. Limaye N, Boon LM, Vikkula M. From germline towards somatic mutations in the pathophysiology of vascular anomalies. Hum Mol Genet. 2009;18:65-74.

24. Kim I, Kim HG, So JN, Kim JH, Kwak HJ, Koh GY. Angiopoietin-1 regulates endothelial cell survival through the phosphatidylinositol 3'-kinase/Akt signal transduction pathway. Circ Res. 2000;86:24-9.

25. Hammill AM, Wentzel M, Gupta A, Nelson S, Lucky A, Elluru R, et al. Sirolimus for the treatment of complicated vascular anomalies in children. Pedriatr Blood Cancer. 2011;57:1018-24.

26. Lackner H, Karastaneva A, Schwinger W, Benesch M, Sovinz P, Seidel M, et al. Sirolimus for the treatment of children with various complicated vascular anomalies. Eur J Pediatr. 2015:174:1579-84.

27. Gagne JJ, Thompson L, O'Keefe K, Kesselheim AS. Innovative research methods for studying treatments for rare diseases: methodological review. BMJ. 2014;349:g6802.

28. Yushkevich PA, Piven J, Hazlett HC, Smith RG, Ho S, Gee JC, et al. Userguided 3D active contour segmentation of anatomical structures: significantly improved efficiency and reliability. Neurolmage. 2006;31:1116-28.

29. Yushkevich P, Gerig G. ITK-SNAP (Version 3.0). http://www.itksnap.org. Accessed 25 Apr 2014

30. IBM SPSS Statistics for Windows (Version 24.0). New York. 2016. https://www.ibm.com Accessed 12 Dec 2016.

31. Adams DM, Trenor CC 3rd, Hammill AM, Vinks AA, Patel MN, Chaudry G, et al. Efficacy and safety of Sirolimus in the treatment of complicated vascular anomalies. Pediatrics. 2016;137:e20153257.

Ready to submit your research? Choose BMC and benefit from:

- fast, convenient online submission

- thorough peer review by experienced researchers in your field

- rapid publication on acceptance

- support for research data, including large and complex data types

- gold Open Access which fosters wider collaboration and increased citations

- maximum visibility for your research: over $100 \mathrm{M}$ website views per year

At $\mathrm{BMC}$, research is always in progress.

Learn more biomedcentral.com/submissions 